\title{
Collapse mechanism and robustness of precast segmental bridges
}

Francis T. K. Au MSc, PhD, CEng, MICE, FIStructE, FHKIE Professor, Department of Civil Engineering, The University of Hong Kong, Hong Kong

Cliff C. Y. Leung BASC, MSC

PhD candidate, Department of Civil Engineering, The University of Hong Kong, Hong Kong
Albert K. H. Kwan BSC, PhD, CEng, MICE, FHKIE

Professor, Department of Civil Engineering, The University of Hong Kong, Hong Kong

In the construction of multi-span precast concrete segmental bridges, in situ stitches are often cast to connect together adjacent cantilevers assembled from precast segments. Since the stitches are often lightly reinforced, the robustness of a segmental bridge could be adversely affected by the capability of the stitches to resist any large variations in moment during extreme events. While most previous studies have focused on methods to measure robustness, there has been little systematic examination of the effects of strength and behaviour of structural components on robustness of structures. As prestressed concrete is relatively non-ductile, finite-element analyses are carried out taking into account the full-range non-linear moment-curvature relationship to examine the formation of plastic hinges and possible collapse mechanisms. Three classes have been proposed for the evaluation of robustness, namely superb, adequate and inadequate. Recommendations to achieve good robustness are also put forward.

\section{Notation}

a

B

b

d

$E_{\mathrm{ps}}$

$E_{\mathrm{s}}$

EI

$f$

$f_{\text {pu }}$

$f_{\mathrm{y}}$

i

K

L

$l_{\mathrm{p}}$

M

$m$ node $a$ of the beam element used strain matrix

node $b$ of the beam element used

effective depth

elastic modulus of prestressing steel

elastic modulus of non-prestressed steel

flexural rigidity

force vector

ultimate strength of prestressing steel

yield strength of non-prestressed steel

ith load step

stiffness matrix

length of element

plastic hinge length

bending moment at a section

bending moment calculated after an iteration step

$n$th iteration step

linear interpolation function at node $a$

linear interpolation function at node $b$

$x$-coordinate in the element axial direction

distance between the critical section and the

point of contraflexure

displacement vector

section curvature

residual section curvature

\section{Introduction}

Although a structure has been designed for the standard load cases at the ultimate limit state (ULS), it may still be subjected to rare extreme loading. Such extreme loading may be so much higher than the standard design loading at ULS that designing for the extreme loading with standard safety factors may be totally unwarranted. Therefore, the concept of structural robustness is often adopted. Structural robustness can be defined as the ability of a structure to guard against disproportionate collapse in the event of a localised failure. Following the Ronan Point incident in the UK in the late 1960s, more research on robustness of buildings has been conducted, which has ultimately led to new design principles and changes to building codes (Alexander, 2004; Beeby, 1999; Ellingwood, 2005; Pearson and Delatte, 2005). Similar work has also focused on bridges (Ghali and Tadros, 1997; Starossek, 2009; Stempfle and Vogel, 2006).

Unlike buildings, bridges have fewer load paths to redistribute loads in case of local failures. Robustness is of concern particularly in multi-span bridges to avoid progressive collapse. If part of a span ruptures, a substantial hogging moment is induced in the deck sections over the adjacent piers. Whether or not progressive failure ensues therefore depends largely on the moment capacity and deformability of these critical deck sections. Multi-span concrete bridges are often constructed using the balanced cantilever method that involves successively extending 
precast segments outwards in a balanced manner and an in situ stitch is cast between the final approaching segments. Benaim (2008) mentioned that for narrow stitches up to $250 \mathrm{~mm}$ wide, non-prestressed longitudinal reinforcement may not be provided. Therefore, the stitch could be a potential weakness, which may trigger progressive collapse under exceptional circumstances.

Most previous studies on the robustness of bridges were based on probabilistic or risk analysis (Baker et al., 2008; Canisius et al., 2007; Starossek and Haberland, 2008). Marjanishvili (2004) proposed qualitative procedures to assess structures for progressive collapse, while Gudmundsson and Izzuddin (2010) further presented a framework for implementation. Seible et al. (2008) conducted tests on the damaging effects of blasting on both reinforced concrete and steel deck and column at the component level. There has been a lack of systematic examination of how the properties of various structural components affect structural integrity (Lee and Sternberg, 2008). Robustness indicators are useful only if accurate prediction of collapse behaviour is available. Examination of the formation of the collapse mechanism in multi-span concrete bridges under extreme events requires a non-linear finite-element method for full-range analysis, which covers material behaviour ranging from the elastic state to that beyond the peak strength, namely the post-peak state.

\section{Method of analysis}

\subsection{Configuration of the bridge analysed}

Figure 1 shows a typical segmental bridge constructed of concrete of cube strength $50 \mathrm{MPa}$ using the balanced cantilever

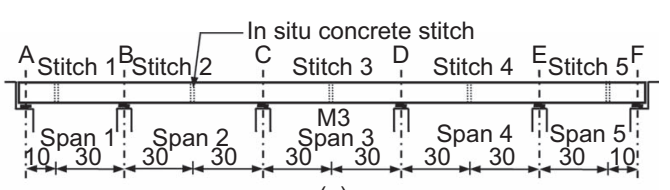

(a)

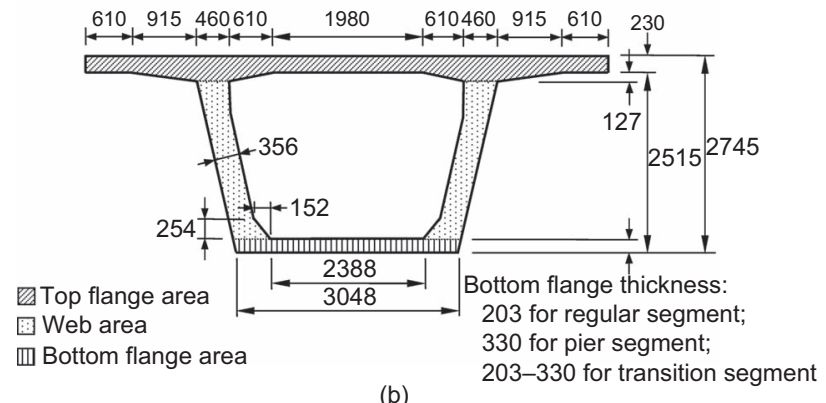

Figure 1. Configuration of the bridge analysed: (a) general arrangement (dimensions: $\mathrm{m}$ ); (b) deck section (not to scale) (dimensions: $\mathrm{mm}$ ) method, which is largely similar to the North Vernon Bridge in Indiana (Prestressed Concrete Institute, 1978). The deck is supported on bearings and is assumed to have the same crosssection except for certain segments with thicker bottom flanges, including the segment above each pier (the pier segment) and those adjacent to the pier segment (the transition segments with linearly varying bottom flange thickness). The bridge has rather low statical indeterminacy and is therefore prone to progressive collapse. The bridge and its variations are to satisfy the standard load cases at ULS.

The cantilever tendons are stressed after erection of each pair of segments. After casting the $200 \mathrm{~mm}$ wide in situ concrete stitch and allowing time for it to gain strength, the continuity tendons of the span are stressed. Each tendon consists of 12 strands of $13 \mathrm{~mm}$ diameter with cross-sectional area per strand of $98.5 \mathrm{~mm}^{2}$, ultimate strength $f_{\text {pu }}$ of $1862 \mathrm{MPa}$ and elastic modulus $E_{\mathrm{ps}}$ of $195 \mathrm{GPa}$. To account for various losses of prestress (Prestressed Concrete Institute, 1978), the effective tendon stress is taken to be $60 \%$ of the ultimate strength. All the cantilever tendons are symmetrical about the pier from which construction begins, while all the continuity tendons over interior spans are symmetrical about the mid-span. Tendons anchored to the same segment joints constitute a tendon group. Additional information on the tendon arrangements is given in Figure 2 and Table 1. Each deck segment is also reinforced by non-prestressed steel with yield strength $f_{\mathrm{y}}$ of $460 \mathrm{MPa}$ and elastic modulus $E_{\mathrm{s}}$ of $200 \mathrm{GPa}$. The amounts of longitudinal non-prestressed steel for the top flange, bottom flange and web as shown in Figure 1(b) are $6266 \mathrm{~mm}^{2}$, $1570 \mathrm{~mm}^{2}$ and $2512 \mathrm{~mm}^{2}$ respectively. Longitudinal nonprestressed steel is not provided to in situ concrete stitches.

\subsection{Full-range non-linear analysis}

\subsubsection{General approach}

Since the bridge deck is essentially a continuous beam with simple supports with negligible axial deformation, it is discretised by beam elements having rotational and vertical translational degrees of freedom at each node for full-range nonlinear analysis. The beam element is accurate and computationally efficient in considering non-linearity and path dependence. The constitutive behaviour of a section, which includes loading and unloading, is governed by the moment-curvature relationship (Figure 3) from section analysis (Au et al., 2011)

\section{1. $M=E I\left(\phi-\phi_{\mathrm{r}}\right)$}

where $M$ is the bending moment, $E I$ is the flexural rigidity that is taken as the slope of the initial elastic branch of the momentcurvature curve, $\phi$ is the section curvature and $\phi_{\mathrm{r}}$ is the residual curvature to account for inelastic behaviour. The use of such $M-\phi$ curves helps to account for the effect of the limited ductility 


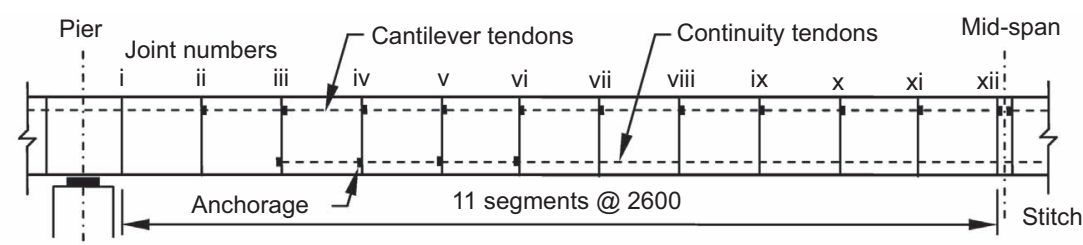

(a)

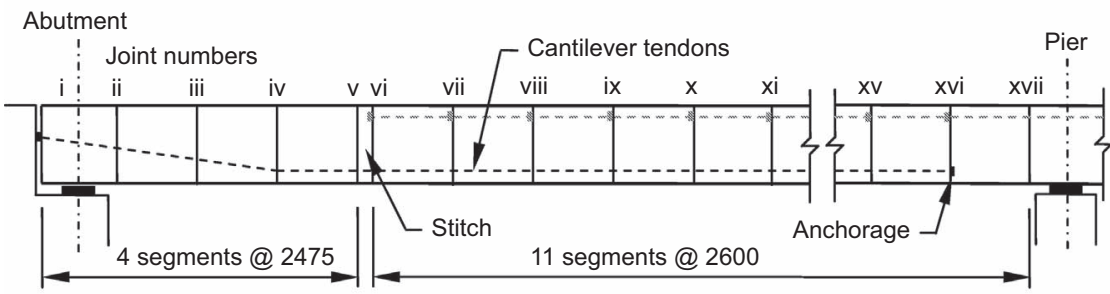

(b)

Figure 2. Tendon arrangements: (a) interior span; (b) end span (dimensions: $\mathrm{mm}$ )

of plastic hinges on the overall structural behaviour. Assuming the tendon eccentricity and other sectional properties to vary linearly along the element, the values of flexural rigidity $E I$ and residual curvature $\phi_{\mathrm{r}}$ within the element can be interpolated from those of nodes $a$ and $b$ at the ends. The deck is assumed to have sufficient shear reinforcement so that shear failure can be ruled out.

Derivation of the force-displacement relationship for each element using the potential energy approach gives the load vector $\boldsymbol{f}$ as
$\boldsymbol{f}=\mathbf{K} \boldsymbol{\delta}-\int \mathbf{B}^{\mathbf{T}}\left[N_{a}(E I)_{a}+N_{b}(E I)_{b}\right]\left(N_{a} \phi_{\mathrm{r} a}+N_{b} \phi_{\mathrm{r} b}\right) \mathbf{B} \mathrm{d} x$

where the stiffness matrix $\mathbf{K}$, the strain matrix $\mathbf{B}$ and the linear interpolation functions $N_{a}$ and $N_{b}$ are given respectively as

\begin{tabular}{|c|c|c|c|}
\hline Tendon group & Anchorage points & Number of tendons & $\begin{array}{l}\text { Depth of tendon centroid } \\
\text { from top of deck }\end{array}$ \\
\hline \multicolumn{4}{|c|}{ Cantilever tendons (Figure 2(a)) } \\
\hline 1 & ii & 4 & \multirow[t]{3}{*}{ Constant at $150 \mathrm{~mm}$} \\
\hline 2 & iii & 4 & \\
\hline $3-13$ & iv-xii & 2 each & \\
\hline \multicolumn{4}{|c|}{ Continuity tendons along interior span (Figure $2(a)$ ) } \\
\hline 1 & iii & 2 & \multirow[t]{4}{*}{ Constant at $2595 \mathrm{~mm}$} \\
\hline 2 & iv & 2 & \\
\hline 3 & $\mathrm{v}$ & 2 & \\
\hline 4 & vi & 2 & \\
\hline \multicolumn{4}{|c|}{ Continuity tendons along end span (Figure 2(b)) } \\
\hline 1 & $i$ and $x v i$ & 2 & $\begin{array}{l}\text { Varies from } 1002 \mathrm{~mm} \text { at i to } \\
2595 \mathrm{~mm} \text { at iv; constant at } \\
2595 \mathrm{~mm} \text { from iv to xvi }\end{array}$ \\
\hline
\end{tabular}

Table 1. Tendon arrangements 


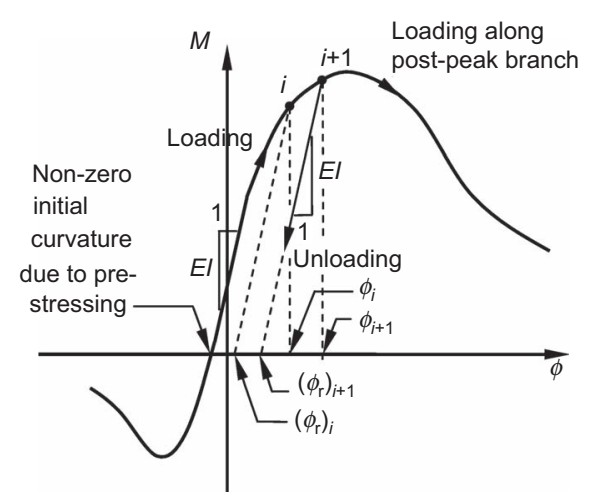

Figure 3. Constitutive model of a prestressed concrete section

4.

$\mathbf{B}=\left[-\frac{6}{L^{2}}+\frac{12 x}{L^{3}} ;-\frac{4}{L}+\frac{6 x}{L^{2}} ; \frac{6}{L^{2}}-\frac{12 x}{L^{3}} ;-\frac{2}{L}+\frac{6 x}{L^{2}}\right]$

5a. $\quad N_{a}=\left(1-\frac{x}{L}\right)$

5b. $\quad N_{b}=\left(\frac{x}{L}\right)$

$\boldsymbol{\delta}$ is the displacement vector; $(E I)_{a}$ and $(E I)_{b}$ are the flexural rigidities at nodes $a$ and $b$ respectively, $\phi_{\mathrm{r} a}$ and $\phi_{\mathrm{r} b}$ are the residual curvatures at nodes $a$ and $b$ respectively; $x$ is the $x$ coordinate in the element axial direction; and $L$ is the length of element. At any loading step $i$, fixed and incremental load or displacement as appropriate are applied upon which iterations are performed to yield a set of nodal displacements, curvatures, residual curvatures and moments that satisfy the $M-\phi$ relationship (Equation 1) within a preset tolerance. At any iteration step $n$ in the $i$ th load step, if the calculated moment $m_{i}^{n}$ corresponding to curvature $\phi_{i}^{n}$ does not satisfy the $M-\phi$ relationship, the updated residual curvature $\left(\varphi_{\mathrm{r}}\right)_{i}^{n+1}$ to be used in the next iteration is given by

$$
\text { 6. }\left(\phi_{\mathrm{r}}\right)_{i}^{n+1}=\phi_{i}^{n}-\frac{M_{i}^{n}}{E I}
$$

where $M_{i}^{n}$ is the moment for curvature $\phi_{i}^{n}$ from the $M-\phi$ relationship. Iterations as shown in Figure 4 continue until the solution satisfies the constitutive relationship by all elements (Au and Leung, 2011). Although the non-linear $M-\phi$ relationship inclusive of the post-peak behaviour has been taken into account, the geometric non-linearity of large deflection is not accounted for. However, this is considered sufficient to evaluate the essential behaviour relevant to robustness of this type of bridges.

\subsubsection{Modelling of the bridge deck}

A symmetrical finite-element mesh is adopted, with details shown in Figure 5 and Table 2. Plastic hinges may form around the in situ stitches and the sections above piers (i.e. pier sections), and hence finer elements are used there. For example, upon imposition of displacements, plastic hinges may form at certain locations where the post-peak branches of the $M-\phi$ relationship (Figure 3) are traced after the moment capacities are reached, while unloading occurs elsewhere. The non-linear analysis helps to decide if onward loading or unloading occurs. The plastic hinge length $l_{\mathrm{p}}$ within which all sections are assumed to proceed along the post-peak branch of the $M-\phi$ relationship is quite controversial, and existing formulae for calculating this value are found to be largely inconsistent (Mendis, 2001). Formulae for estimation of plastic hinge length $l_{\mathrm{p}}$ by Sawyer (1964), Corley (1966) and Mattock (1967) are respectively

7a. $\quad l_{\mathrm{p}}=0 \cdot 25 d+0 \cdot 075 z$

7b. $l_{\mathrm{p}}=d / 2+0 \cdot 2 z / \sqrt{d}(d$ and $z$ in inches $)$

7c. $\quad l_{\mathrm{p}}=0 \cdot 5 d+0 \cdot 05 z$

where $d$ is the effective depth and $z$ is the distance between the critical section and the point of contraflexure. Taking $d=$ $2595 \mathrm{~mm}$ and $z=30000 \mathrm{~mm}$ for extreme scenarios in which certain parts have ruptured, the above estimates of $l_{\mathrm{p}}$ are $2899 \mathrm{~mm}, 1892 \mathrm{~mm}$ and $2798 \mathrm{~mm}$ respectively. As parametric study shows that the outcome is not too sensitive to the plastic hinge length, it is simply taken as the overall depth, namely $2745 \mathrm{~mm}$.

\section{Variation of internal moments and formation of collapse mechanisms}

Displacement is gradually applied to the mid-span of span 3 (i.e. M3) to simulate an extreme unforeseen load there, as for example when a large boulder falls onto a hillside viaduct during a mudslide. As the ensuing changes in deck moments and the possible sequence of plastic hinge formation will affect the vulnerability of the bridge to progressive collapse, three different scenarios with some variations of properties from those specified in Section 2 are examined, namely, (a) scenario A: moment capacities at pier sections $\mathrm{C}$ and $\mathrm{D}$ are not reached; (b) scenario B: moment capacities at pier sections $\mathrm{C}$ and $\mathrm{D}$ are reached; and $(c)$ scenario $C$ : moment capacities at most critical 


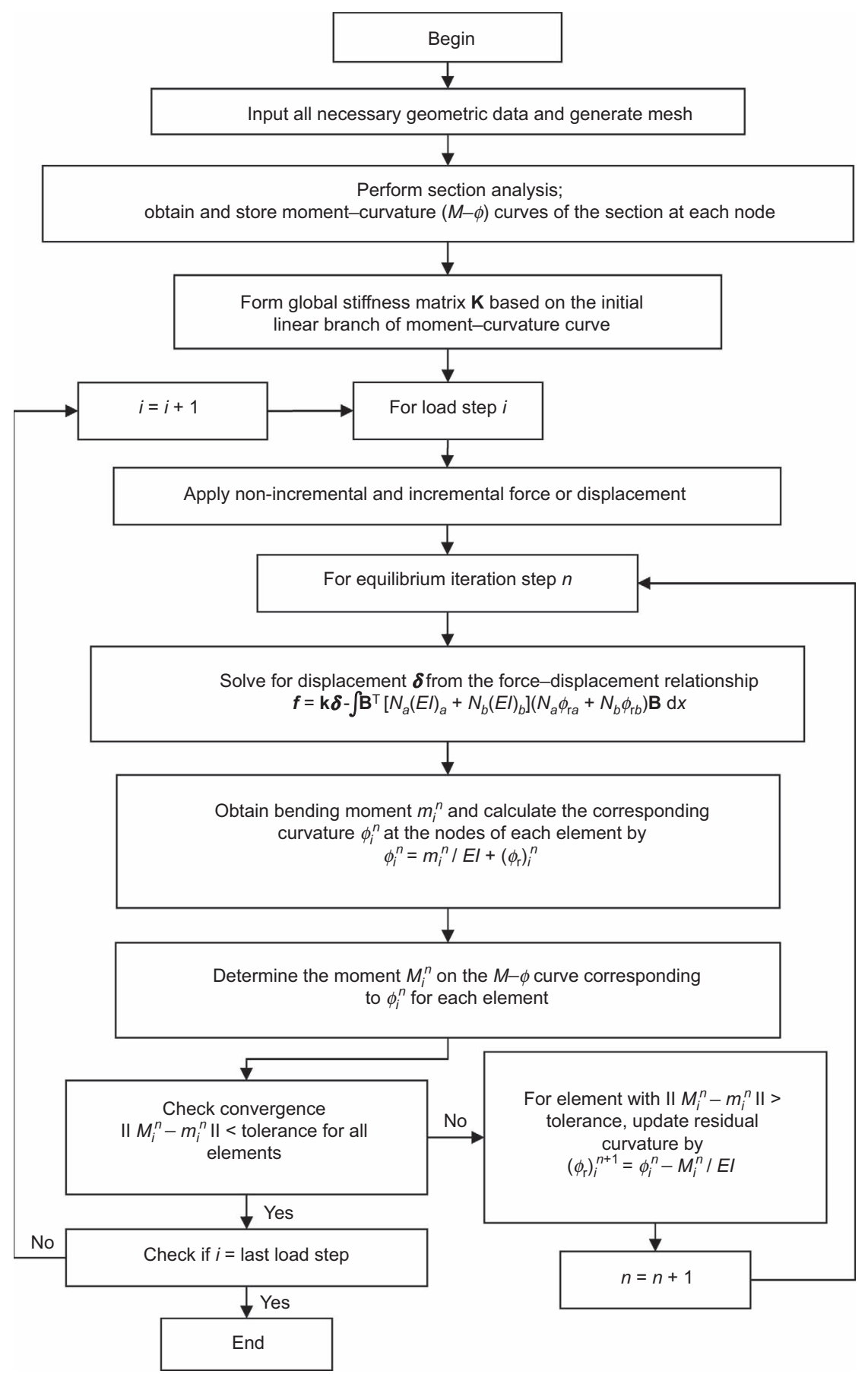

Figure 4. Flowchart of finite-element analysis

sections are reached. These cases are further analysed to examine possible outcomes of no collapse, limited collapse and progressive collapse. It is assumed that a plastic hinge is formed once the moment capacity is reached and deformation is continued.

\subsection{Scenario A}

The tendon and reinforcement arrangement is that in Section 2. Figure 6 shows the variation of deck moments in scenario $A$ under permanent loading and imposed displacement at M3, where positive values denote hogging moments. Figure 7 
Collapse mechanism and

robustness of precast

segmental bridges

$\mathrm{Au}$, Leung and Kwan

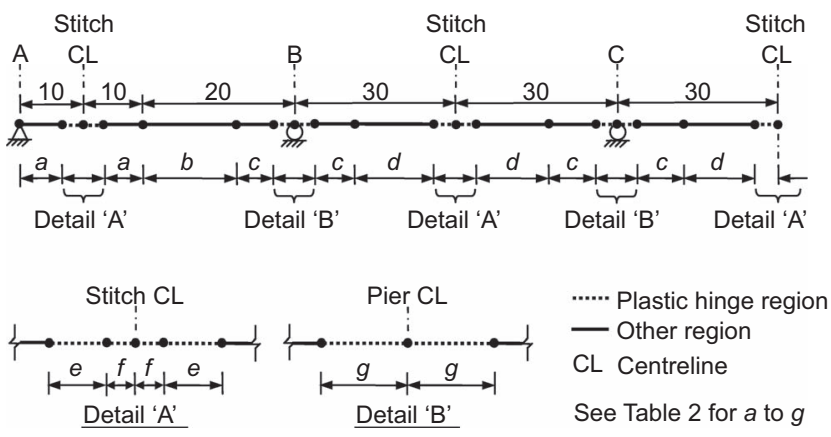

Figure 5. Finite-element mesh for analysis (dimensions in $\mathrm{m}$ )

shows the vertical displacements of deck where positive values are upward. Failure at a section is denoted by a cross. These sign conventions hold hereafter unless otherwise stated. Figure 6 also shows extremely low hogging moment capacities at in situ stitches and extremely low sagging moment capacities at pier sections as they are not required by the standard load cases.

Figure 6(a) shows the deck moments when M3 deflects downwards by $25 \mathrm{~mm}$, when the moments still stay within the moment capacities. When the deflection at M3 reaches $200 \mathrm{~mm}$, stitches 2 and 4 in the adjacent spans fail under hogging moments. As the deflection at M3 increases to $325 \mathrm{~mm}$, the sagging moment there has reached its capacity, causing stitch 3 to fail and giving the deck moment in Figure 6(b). The deformed shape in Figure 7(a) clearly shows the 'kinks' of significant curvatures at stitches 2, 3 and 4 . Figure 7(b) shows the deformed shape when the deflection at M3 reaches $750 \mathrm{~mm}$, with pronounced hinging at stitches 2, 3 and 4. When the deflection at M3 reaches $1250 \mathrm{~mm}$, the sagging moments induced at pier sections $\mathrm{B}$ and $\mathrm{E}$ then cause flexural failure there. The deck moment in Figure 6(c) shows that five plastic hinges are formed. The sequence of plastic

\begin{tabular}{lrc}
\hline Region & Length: $\mathrm{mm}$ & No. of equal elements \\
\hline $\mathrm{a}$ & 8627 & 8 \\
$\mathrm{~b}$ & 11814 & 6 \\
$\mathrm{c}$ & 6814 & 8 \\
$\mathrm{~d}$ & 13628 & 6 \\
$\mathrm{e}$ & 1272 & 4 \\
$\mathrm{f}$ & 100 & 3 \\
$\mathrm{~g}$ & 1372 & 4
\end{tabular}

Table 2. Details of finite-element mesh

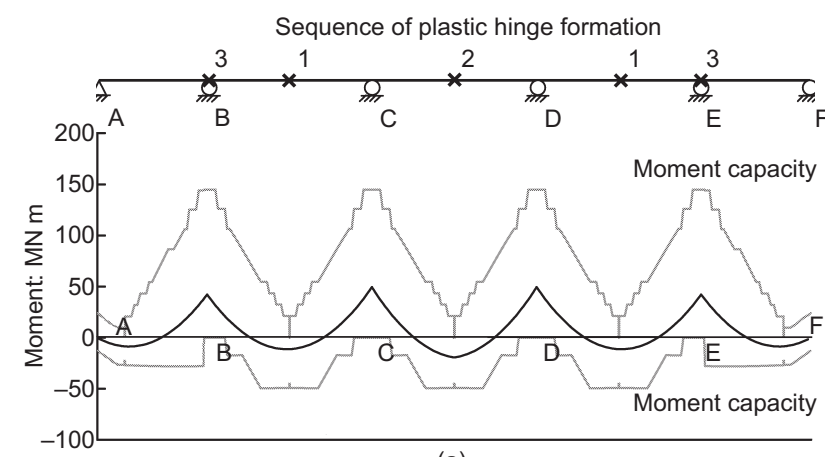

(a)

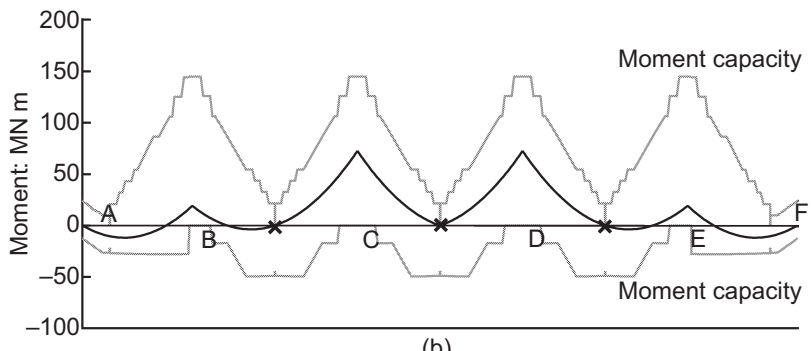

(b)

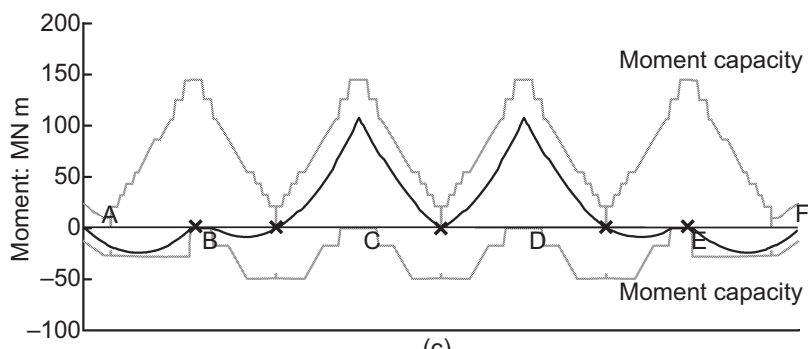

(c)

Figure 6. Variation of deck moments in scenario A: (a) early loading stage (max. deflection $=25 \mathrm{~mm}$ ); (b) after failure at M3 (max. deflection $=325 \mathrm{~mm}$ ); (c) after failure at pier sections $B$ and $\mathrm{E}(\mathrm{max}$. deflection $=1250 \mathrm{~mm})$

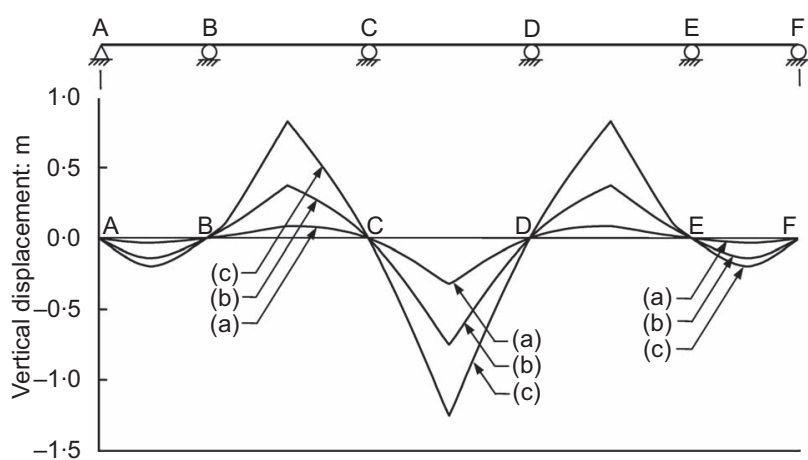

Figure 7. Variation of deck displacements in scenario $A$ : (a) failure at M3; (b) after failure at M3; (c) failure at pier sections $B$ and $E$ 
Bridge Engineering

Volume 167 Issue BE4
Collapse mechanism and

robustness of precast

segmental bridges

$\mathrm{Au}$, Leung and Kwan hinge formation is summarised in the bridge elevation in Figure 6. The deformed shape in Figure 7(c) is characterised by 'kinks' not only at stitches 2, 3 and 4, but also at pier sections $\mathrm{B}$ and $\mathrm{E}$. The moment at each plastic hinge reduces with further rotation along the post-peak branch of its $M-\phi$ curve and hence the moments at the plastic hinges become extremely low. Even if the deflection at M3 continues to increase, the deck moments do not depart much from those shown in Figure 6(c).

Since none of the spans has collapsed and no mechanism is formed, one may say that the bridge has superb robustness. From Figures 6(c) and 7(c), it is possible to conclude that a necessary condition for this superb robustness is provision of adequate moment capacities at pier sections $\mathrm{C}$ and D. Examination of the deck moments over span 2 in Figure 6(c) suggests that the maximum moment at pier section $\mathrm{C}$ can be estimated from an equivalent cantilever having $\mathrm{C}$ as fixity with a length lying between $50 \%$ and $100 \%$ of span 2 .

\subsection{Scenario B}

In scenario $\mathrm{B}$, the hogging moment capacities in the segments adjacent to the piers are reduced to approximately $70 \%$ of those in scenario A so as to examine the effects of failure of pier sections $\mathrm{C}$ and D on robustness. Figures 8 and 9 show respectively the variations of deck moments and vertical displacements under permanent loading and imposed displacement at M3.

When the deflection at M3 increases to $360 \mathrm{~mm}$, flexural failure has occurred at M3 giving the deck moments in Figure 8(a). As the deflection at M3 reaches $650 \mathrm{~mm}$, stitches 2 and 4 fail in hogging moment. Unlike scenario A, because of the reduced flexural stiffness and strength of the segments adjacent to the piers in scenario $\mathrm{B}$, the sagging moment increases more rapidly at M3, causing failure there before stitches 2 and 4. When the deflection at M3 reaches $2905 \mathrm{~mm}$ as shown in Figure 9(a), the hogging moments at pier sections $\mathrm{C}$ and D reach their moment capacities (Figure 8(b)), which are about to cause flexural failure there. Further increase of the deflection at M3 to $2915 \mathrm{~mm}$ causes not only flexural failure at pier sections $\mathrm{C}$ and $\mathrm{D}$, but also formation of plastic hinges at stitches 1 and 5 because of excessive hogging moments. As the deflection at M3 reaches $2925 \mathrm{~mm}$, the flexural failure at pier sections $\mathrm{C}$ and $\mathrm{D}$ has progressed so much along the post-peak branches of their $M-\phi$ curves that the moments there have decreased to nearly zero, giving the deck moment in Figure $8(\mathrm{c})$. The three well-developed plastic hinges in span 3 therefore lead to its collapse, as shown in the deck displacement in Figure 9(b).

One critical issue is whether the collapse of span 3 will trigger progressive collapse. Immediately prior to the flexural failure

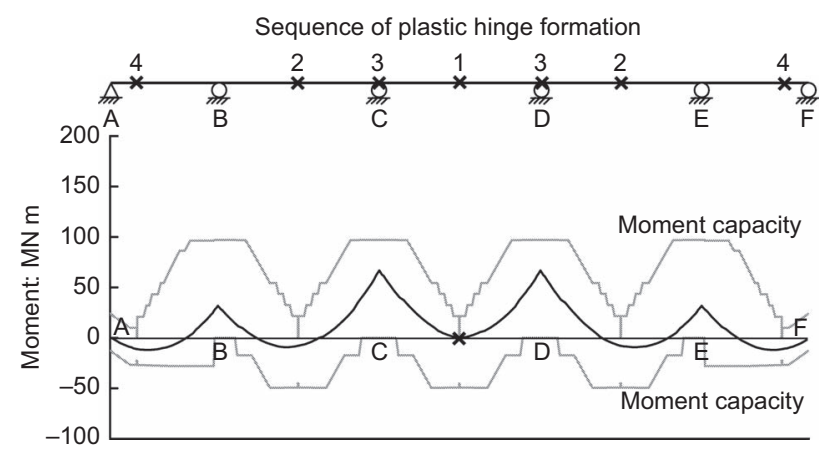

(a)

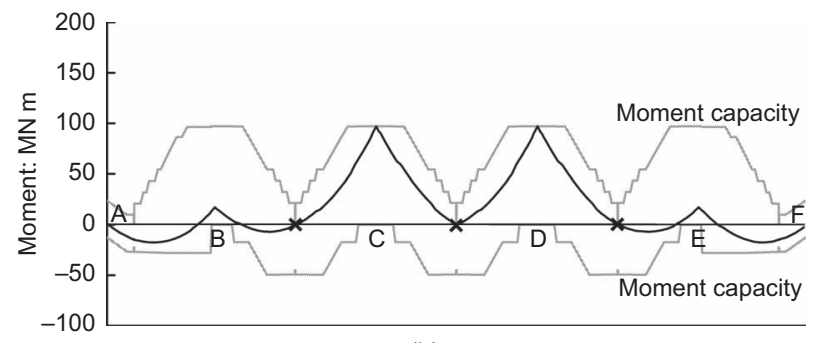

(b)

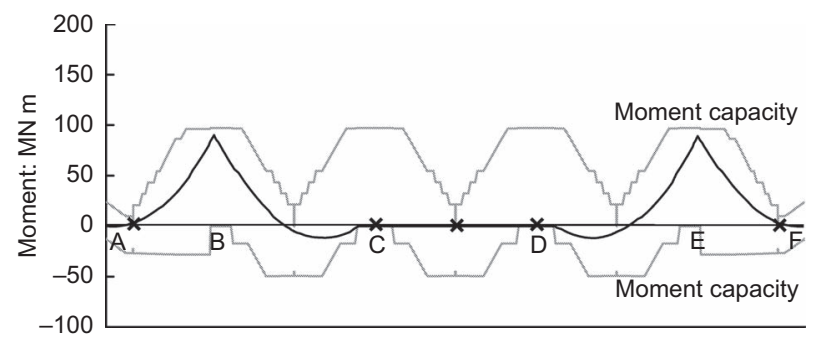

(c)

Figure 8. Variation of deck moments in scenario B: (a) after failure at M3 (max. deflection $=360 \mathrm{~mm}$ ); $($ b) prior to failure at pier sections $C$ and $D$ (max. deflection $=2905 \mathrm{~mm}$ ); (c) after failure at pier sections $C$ and $D(\max$. deflection $=2925 \mathrm{~mm}$ )

at pier sections $\mathrm{C}$ and $\mathrm{D}$, the deck moments from end $\mathrm{A}$ to stitch 2 and from stitch 5 to end $F$ are relatively small, as shown in Figure 8(b), which are predominantly sagging except for the vicinity of pier sections B and E. The corresponding deck displacements in Figure 9(a) show predominantly sagging curvatures in spans 1 and 5, and hogging curvatures in spans 2 and 4. With the flexural failure at pier sections $C$ and $D$, substantial changes to the deck moments and displacements ensue. Stitches 2 and 4, which have previously formed plastic hinges under hogging moments, are put in slight sagging moments after the reversal. At the same time, large parts of spans 1, 2, 4 and 5 are caused to take substantial hogging moments (Figure $8(\mathrm{c})$ ), resulting in reversals of deflections (Figure 9(b)). 
Collapse mechanism and

robustness of precast

segmental bridges

$\mathrm{Au}$, Leung and Kwan

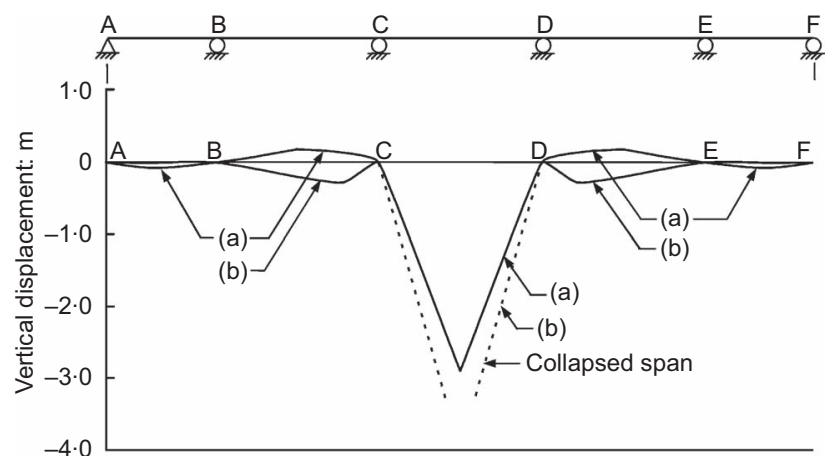

Figure 9. Variation of deck displacements in scenario B: (a) prior to failure at pier sections $C$ and D; (b) collapse of span 3

Collapse is confined to span 3 only if the increased hogging moments at pier sections $\mathrm{B}$ and $\mathrm{E}$ do not exceed their corresponding moment capacities, when spans 2 and 4 act effectively as new end spans after the collapse of span 3. Since collapse is limited to one single span, one may say that the bridge has adequate robustness. To achieve adequate robustness, in the extreme event of loss of a certain span for whatever reasons, the adjacent spans should have sufficient moment capacities to resist the increased sagging and hogging moments when they behave as the new end spans.

\subsection{Scenario C}

In scenario $\mathrm{C}$, the hogging moment capacities in the segments adjacent to the piers are reduced to approximately $55 \%$ of those in scenario A so as to examine the effects of formation of multiple plastic hinges at pier sections during the failure process on robustness. Figures 10 and 11 show respectively the variations of deck moments and vertical displacements under permanent loading and imposed displacement at M3.

Because of the further reduced flexural stiffness and strength of the segments adjacent to the piers, sagging moment increases rapidly at M3. When the deflection at M3 increases to $385 \mathrm{~mm}$, flexural failure has occurred at M3. As the deflection at M3 reaches $1505 \mathrm{~mm}$, stitches 2 and 4 fail in hogging moment. When the deflection at M3 reaches $2745 \mathrm{~mm}$ (Figure 11(a)), the hogging moments at pier sections $\mathrm{C}$ and $\mathrm{D}$ reach their moment capacities (Figure 10(a)), which are about to cause flexural failure there. At that time, the hogging moments at pier sections $\mathrm{B}$ and $\mathrm{E}$ are still relatively low. Further increase of the deflection at M3 to $2750 \mathrm{~mm}$ causes not only flexural failure at pier sections $\mathrm{C}$ and $\mathrm{D}$, but also formation of plastic hinges at stitches 1 and 5 because of excessive hogging moments.

As the deflection at M3 reaches $2765 \mathrm{~mm}$, the hogging moments at pier sections $\mathrm{B}$ and $\mathrm{E}$ have reached their respective

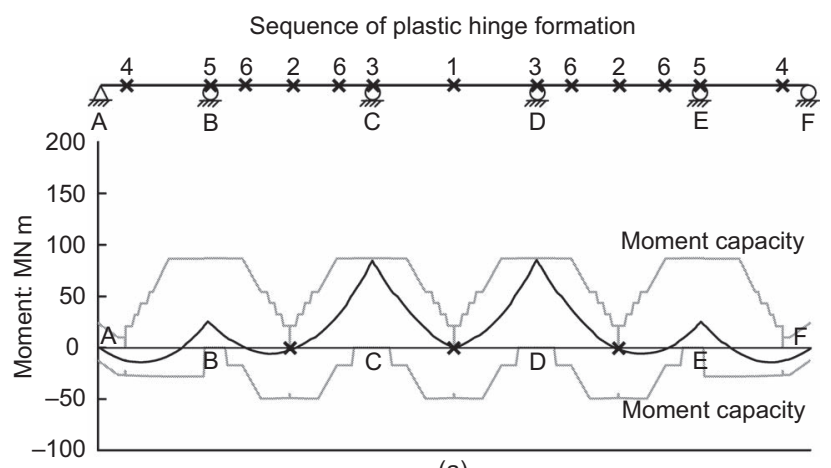

(a)
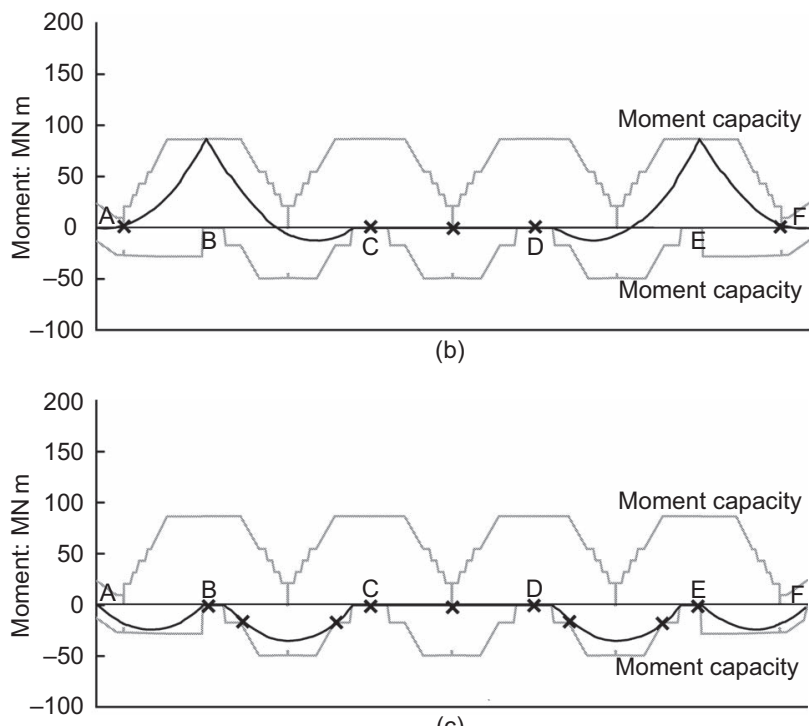

(c)

Figure 10. Variation of deck moments in scenario $C$ : (a) prior to failure at pier sections $C$ and $D(\max$. deflection $=2745 \mathrm{~mm})$; $(b)$ after failure at pier sections $C$ and $D(\max$. deflection $=2765 \mathrm{~mm}$ ); (c) after failure at pier sections $B$ and $E$ ( $m a x$. deflection $=2775 \mathrm{~mm}$ )

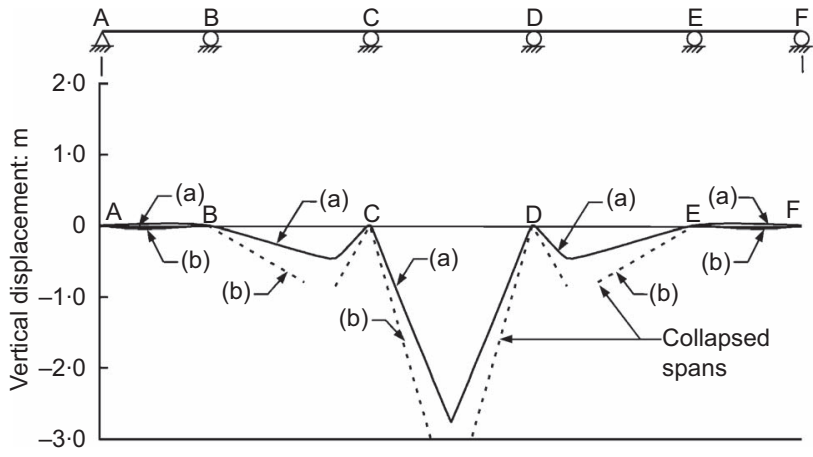

Figure 11. Variation of deck displacements in scenario C: (a) failure at pier sections $C$ and $D$; (b) failure at pier sections $B$ and $E$ 
Bridge Engineering

Volume 167 Issue BE4
Collapse mechanism and

robustness of precast

segmental bridges

$\mathrm{Au}$, Leung and Kwan moment capacities, and the flexural failure at pier sections $\mathrm{C}$ and $\mathrm{D}$ has progressed so much along the post-peak branches of their $M-\phi$ curves that the moments there have decreased to nearly zero, giving the deck moment as shown in Figure 10(b). The three well-developed plastic hinges in span 3 therefore lead to its collapse. After this, spans 2 and 4 effectively act as end spans, leading to reversal from hogging moments to sagging moments in the regions from stitch 2 to pier section $\mathrm{C}$ and from pier section D to stitch 4 , as well as substantial increase of hogging moments around pier sections B and E.

Further increase of the deflection at M3 to $2775 \mathrm{~mm}$ causes failures at the pier sections B and E, resulting in substantial rearrangement of deck moments (Figure 10(c)). With the reduction of moments at pier sections $\mathrm{B}, \mathrm{C}, \mathrm{D}$ and $\mathrm{E}$ to nearly zero, spans 1, 2, 4 and 5 then act as if they were simply supported. In particular, the rapid increase in sagging moments in spans 2 and 4 causes formation of plastic hinges in sagging moments at locations close to the piers, as the prevailing moments there under standard load cases are essentially hogging. These additional plastic hinges therefore trigger the collapse of spans 2 and 4 . The progressive failure of the bridge deck is evident and the deck is said to have inadequate robustness.

\section{Effects of providing top reinforcement to in situ concrete stitches}

Examination of the previous scenarios shows that the collapse of a bridge designed for standard load cases under extreme circumstances is often triggered by failure of sections by moments of signs unexpected in regular design. A parametric study is therefore carried out with the bridge described in Section 2 to examine the effects of providing nominal top reinforcement across in situ concrete stitches on the global bridge behaviour under an extreme event. Table 3 shows the six models investigated, namely models A1 to A6, with different numbers of prestressing strands provided to each of the in situ stitches. The strands are anchored to blisters located beneath the soffit of the top flange and effectively prestressed

\begin{tabular}{lcc}
\hline Model & $\begin{array}{c}\text { No. of prestressing } \\
\text { strands }\end{array}$ & $\begin{array}{c}\text { Area of prestressing } \\
\text { steel: } \mathrm{mm}^{2}\end{array}$ \\
\hline A1 & 0 & 0 \\
A2 & 6 & 592 \\
A3 & 12 & 1183 \\
A4 & 18 & 1775 \\
A5 & 24 & 2366 \\
A6 & 30 & 2958
\end{tabular}

Table 3. Amount of prestressing strands in a stitch to a relatively low stress level of $0 \cdot 2 f_{\mathrm{pu}}$. The deformed shapes for models A1 and A4 just before flexural failure at M3 are plotted in Figure 12. Without the top reinforcement across in situ stitches in model A1, stitches 2 and 4 should have already formed plastic hinges in hogging moments, as characterised by the 'kinks' at these stitches, before the flexural failure at M3. However, by providing a relatively small amount of top reinforcement across in situ stitches in model A4, the integrity of stitches 2 and 4 is preserved, thereby reducing the chance of forming a collapse mechanism.

The effectiveness of providing top reinforcement across stitches is further studied by examining the variations of moments at stitches 2 and 4 with imposed deflection for various models. Because of symmetry, only stitch 2 is examined. The development of deck moments at critical sections with reference to the case of permanent loading may be described by the residual strength utilisation factor (RSUF), which is defined by the ratio of the remaining strength utilised to the absolute value of the entire remaining strength. For convenience, RSUF is taken to be positive for sagging moments and negative for hogging moments. In other words, for the case of permanent loading, RSUF is zero, whereas for the case when the moment capacity is reached, RSUF is 1 or -1 . Results of RSUF for models A1, A2 and A4 in Figure 13 show that, while the development of moment at M3 with imposed deflection there is little affected by the provision of top reinforcement at in situ stitches, the development of hogging moments at the in situ stitches in the adjacent spans is substantially affected by such provision of top reinforcement there. For example, if no top reinforcement is provided across the in situ stitches (i.e. model A1), stitches 2 and 4 will fail in hogging moments at imposed deflection at $\mathrm{M} 3$ of $200 \mathrm{~mm}$. By providing about $5 \cdot 8 \%$ of the amount of tendons at interior supports in scenario $\mathrm{A}$ across each of the in situ stitches (i.e. model A4), stitches 2 and 4 are prevented from failure in hogging moments before the

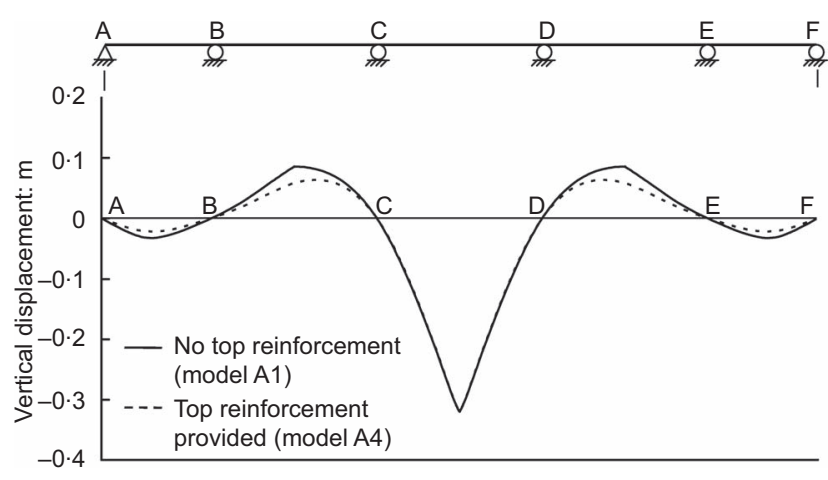

Figure 12. Deck displacements for stitches with and without top reinforcement 


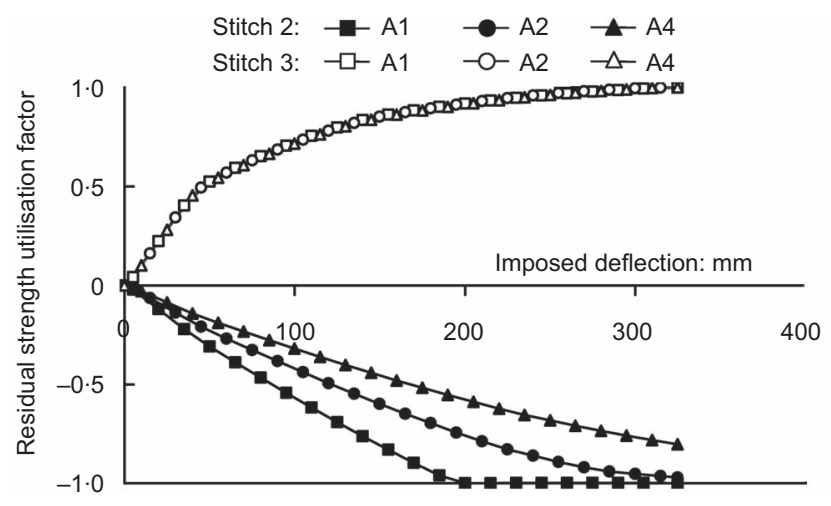

Figure 13. Variations of moments in stitches 2 and 3 with imposed deflection

failure at M3 in sagging moment at an imposed deflection there of around $350 \mathrm{~mm}$. Therefore by providing a nominal amount of top reinforcement across the in situ stitches, the bridge is maintained intact for a longer period during an extreme event.

\section{Overall assessment and recommendations for design}

From the above analyses of precast concrete segmental bridges, the following classification of robustness is proposed.

(a) Superb robustness: no collapse of any span occurs when an unforeseen load is applied. Upon imposition of displacement to simulate the unforeseen load, the structure is able to deform at reasonable resistance in spite of formation of plastic hinges.

(b) Adequate robustness: collapse of at most one span may occur when an unforeseen load is applied there. Upon imposition of displacement to simulate the unforeseen load, the resistance drops to almost zero after formation of plastic hinges, which are mostly located in the collapsed span.

(c) Inadequate robustness: progressive collapse of more than one span may occur when an unforeseen load is applied. Upon imposition of displacement to simulate the unforeseen load, the resistance drops to almost zero after formation of plastic hinges spread over a few spans.

Figure 14 summarises the load-deflection relationship at M3 in various scenarios. In particular, some key points are identified by labels, each comprising a letter and a number to denote key stages in each extreme event, such as formation of plastic hinges. For convenience, scenarios $\mathrm{A}, \mathrm{B}$ and $\mathrm{C}$ are denoted by $\mathrm{A}, \mathrm{B}$ and $\mathrm{C}$ respectively, while $\mathrm{AR}$ denotes scenario A with top reinforcement of model A4 provided across in situ stitches. The numbers come from the sequence of plastic hinge

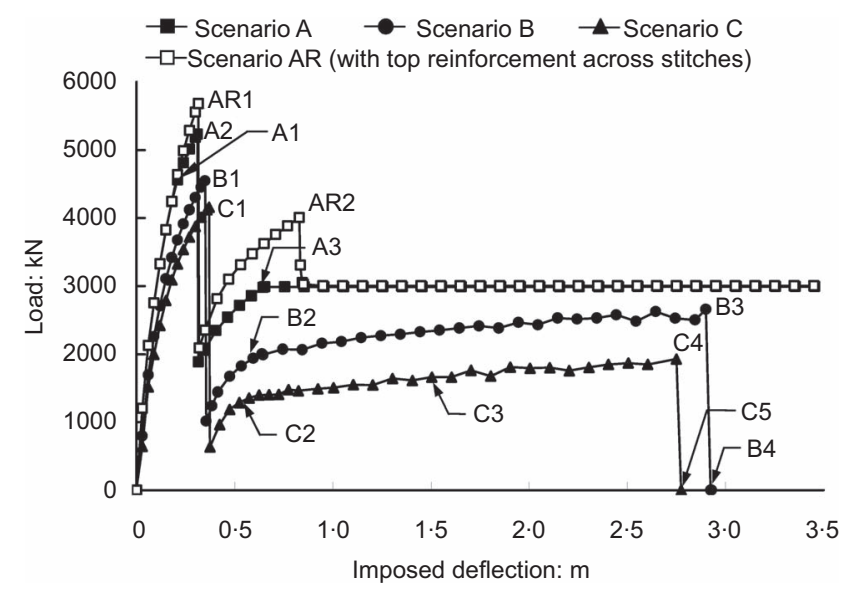

Figure 14. Summary of load-deflection relationship at M3 for various scenarios

formation shown previously in Figures 6,8 and 10, as appropriate.

The load-deflection curves share the common property of increasing resistance up to deflections around $300-400 \mathrm{~mm}$, followed by an abrupt drop associated with flexural failure at M3. Thereafter the resistance increases again possibly until something drastic happens. The graph of scenario A shows that its resistance reaches a plateau after the formation of five plastic hinges in three stages and maintains its ability to deform further, which explains its superb robustness. The graph of scenario $\mathrm{B}$ shows an abrupt reduction in resistance after the formation of seven plastic hinges in four stages. As it results in collapse of a span without spreading to adjacent spans, it has adequate robustness. The graph of scenario $\mathrm{C}$ shows an abrupt reduction in resistance after the formation of 13 plastic hinges in six stages, with the last two stages occurring almost at the same time. As the unforeseen load on span 3 results in collapse of not only span 3, but also the adjacent spans, it has inadequate robustness.

Compared with scenario A, providing top reinforcement of model A4 across in situ stitches strengthens the bridge up to an imposed deflection of $830 \mathrm{~mm}$, after which the resistance drops to virtually the same value as in scenario A with ability to deform further. This is also a case of superb robustness. These results reveal that, even though a bridge is designed for the standard load cases at ULS, different performance in robustness is possible.

As performance in robustness is significantly affected by the full-range behaviour of plastic hinges at susceptible locations including the in situ stitches and pier sections, analyses by imposed displacement at the in situ stitches are desirable. 
Various susceptible locations should be examined to explore possible progressive collapse. A comprehensive evaluation of robustness should include not only unforeseen loads on the deck, but also possible uplift at deck ends due to unforeseen loads, loss of supports, and so on.

To ensure the robustness of a bridge, any span should be designed for the deck moments after the adjacent span has collapsed as if the remaining span has become a new end span. Although analysis of standard load cases may indicate absence of internal force of certain sign (e.g. hogging moment at in situ stitches), it is still desirable to provide nominal resistance against such unforeseen internal forces for the sake of robustness. If possible, a bridge should be designed to achieve superb or adequate robustness.

\section{Conclusions}

A finite-element method has been formulated to analyse multispan precast concrete segmental bridges taking into account the full-range, non-linear, moment-curvature relationship of prestressed concrete sections to examine the formation of plastic hinges and possible collapse mechanisms. It is found that, although a bridge is designed for standard load cases at ULS, it may still be vulnerable to progressive collapse in case of extreme events. A typical five-span precast concrete segmental bridge is studied and an unforeseen accidental load on a span is simulated by imposed displacement at mid-span. Various scenarios with slightly different moment capacities are considered, which give rather different responses to monotonic increasing imposed displacements. Depending on the occurrence or otherwise and extent of collapse, the robustness is classified as superb, adequate and inadequate. Various measures to improve robustness are examined. The provision of top reinforcement across in situ stitches is also found to be conducive to robustness.

\section{Acknowledgements}

The study is supported by Research Grants Council of the Hong Kong Special Administrative Region, China (RGC Project No. HKU 710807E), and the Small Project Funding and the HKU SPACE Research Fund of The University of Hong Kong.

\section{REFERENCES}

Alexander S (2004) New approach to disproportionate collapse. The Structural Engineer 82(23-24): 14-18.

Au FTK and Leung CCY (2011) Full-range analysis of multi-span prestressed concrete segmental bridges. Proceedings of the 12th East Asia-Pacific Conference on Structural Engineering and Construction, Hong Kong, EASEC12-529.

Au FTK, Leung CCY and Kwan AKH (2011) Flexural ductility and deformability of reinforced and prestressed concrete sections. Computers and Concrete 8(4): 473-489.
Baker JW, Schubert M and Faber MH (2008) On the assessment of robustness. Structural Safety 30(3): 253-267.

Beeby AW (1999) Safety of structures, and a new approach to robustness. The Structural Engineer 77(4): 16-21.

Benaim R (2008) The Design of Prestressed Concrete Bridges. Taylor \& Francis, Oxfordshire, UK.

Canisius TDG, Sørensen JD and Baker JW (2007) Robustness of structural systems - a new focus for the joint committee on structural safety (JCSS). In Proceedings of the 10th International Conference on Applications of Statistics and Probability in Civil Engineering, Tokyo, Japan. Taylor \& Francis, London, UK.

Corley WG (1966) Rotational capacity of reinforced concrete beams. Journal of the Structural Division 92(ST5): 121126.

Ellingwood BR (2005) Building design for abnormal loads and progressive collapse. Computer-Aided Civil and Infrastructure Engineering 20(3): 194-205.

Ghali A and Tadros G (1997) Bridge progressive collapse vulnerability. Journal of Structural Engineering 123(2): 227231.

Gudmundsson GV and Izzuddin BA (2010) The 'sudden column loss' idealisation for disproportionate collapse assessment. The Structural Engineer 88(6): 22-26.

Lee GC and Sternberg E (2008) A new system for preventing bridge collapses. Issues in Science and Technology 24(3): 31-36.

Mattock AH (1967) Discussion of 'Rotational capacity of reinforced concrete beams' by W. G. Corley. Journal of the Structural Division, ASCE 111(4): 871-888.

Marjanishvili SM (2004) Progressive analysis procedure for progressive collapse. Journal of Performance of Constructed Facilities 18(2): 79-85.

Mendis P (2001) Plastic hinge lengths of normal and high strength concrete in flexure. Advances in Structural Engineering 4(4): 189-195.

Pearson C and Delatte N (2005) Ronan Point Apartment tower collapse and its effect on building codes. Journal of Performance of Constructed Facilities 19(2): 172-177.

Prestressed Concrete Institute (1978) Precast Segmental Box Girder Bridge Manual. Prestressed Concrete Institute, Chicago, IL, USA.

Sawyer HA (1964) Design of concrete frames for two failure stages. Proceedings of the International Symposium on the Flexural Mechanics of Reinforced Concrete, Miami, pp. 405-431.

Seible F, Hegemier G, Karbhari VM et al. (2008) Protection of our bridge infrastructure against man-made and natural hazards. Structure and Infrastructure Engineering 4(6): 415-429.

Starossek U (2009) Avoiding disproportionate collapse of major bridges. Structural Engineering International: Journal of the International Association for Bridge and Structural Engineering (IABSE) 19(3): 289-297.

Starossek U and Haberland M (2008) Measures of structural 
robustness - requirements and applications. Proceedings of the 2008 Structures Congress - Structures Congress 2008:

Crossing the Borders, Vancouver, pp. 24-26.

Stempfle $\mathrm{H}$ and Vogel T (2006) Robustness of highway overpasses. Proceedings of the 3rd International Conference on Bridge Maintenance, Safety and Management - Bridge Maintenance, Safety, Management, Life-Cycle Performance and Cost, Porto, pp. 793-799.

\section{WHAT DO YOU THINK?}

To discuss this paper, please email up to 500 words to the editor at journals@ice.org.uk. Your contribution will be forwarded to the author(s) for a reply and, if considered appropriate by the editorial panel, will be published as discussion in a future issue of the journal.

Proceedings journals rely entirely on contributions sent in by civil engineering professionals, academics and students. Papers should be 2000-5000 words long (briefing papers should be 1000-2000 words long), with adequate illustrations and references. You can submit your paper online via www.icevirtuallibrary.com/content/journals, where you will also find detailed author guidelines. 